\title{
Cambios y continuidades en el pacto colonial en la Amazonía. El caso de los indios Chasutas del Huallaga Medio a finales del siglo XIX
}

Changements et continuités du pacte colonial en Amazonie. Le cas des indiens Chasutas du Moyen Huallaga à la fin du XIXe siècle

Changes and continuities in the colonial pact in Amazonia. The case of Chasuta at the end of $19^{\text {th }}$ century

\section{Frederica Barclay}

\section{OpenEdition}

\section{Journals}

Edición electrónica

URL: http://journals.openedition.org/bifea/6994

DOI: 10.4000/bifea.6994

ISSN: 2076-5827

Editor

Institut Français d'Études Andines

Edición impresa

Fecha de publicación: 1 agosto 2001

Paginación: 187-210

ISSN: 0303-7495

Referencia electrónica

Frederica Barclay, «Cambios y continuidades en el pacto colonial en la Amazonía. El caso de los indios Chasutas del Huallaga Medio a finales del siglo XIX », Bulletin de l'Institut français d'études andines [En línea], 30 (2) | 2001, Publicado el 08 agosto 2001, consultado el 10 diciembre 2020. URL http://journals.openedition.org/bifea/6994 ; DOI : https://doi.org/10.4000/bifea.6994

\section{(c) (†) $\ominus$}

Les contenus du Bulletin de l'Institut français d'études andines sont mis à disposition selon les termes de la licence Creative Commons Attribution - Pas d'Utilisation Commerciale - Pas de Modification 4.0 International. 


\title{
CAMBIOS Y CONTINUIDADES EN EL PACTO COLONIAL EN LA AMAZONÍA. EL CASO DE LOS INDIOS CHASUTAS DEL HUALLAGA MEDIO A FINALES DEL SIGLO XIX
}

\author{
Frederica BARCLAY
}

\section{Resumen}

Este artículo analiza el levantamiento chasuta ocurrido en 1893 en el Medio Huallaga, como el resultado de lo que los indígenas locales percibieron como la ruptura del pacto colonial que les garantizaba determinados derechos y prerrogativas y establecía sus obligaciones frente al Estado. Sugiere que la disolución de este ordenamiento de origen misional y colonial, condujo a la desintegración social de los llamados chasutas y aceleró los procesos impulsados por el auge gomero.

Palabras claves: Indígenas amazónicos, pueblos indígenas, chasutas, Amazonía, Loreto, Huallaga, Mainas, misiones, levantamientos, ciudadanía étnica.

\section{CHANGEMENTS ET CONTINUITÉS DU PACTE COLONIAL EN AMAZONIE. LE CAS DES INDIENS CHASUTAS DU MOYEN HUALLAGA À LA FIN DU XIXe SIÈCLE}

\section{Résumé}

Cet article analyse le soulèvement Chasuta de 1893 dans la région du moyen Huallaga, comme résultat de ce que les indigènes perçurent comme une rupture du pacte colonial qui leur assurait certains droits et privilèges et établissait leurs devoirs envers l'État. L' article suggère que la dissolution de cet ordre d'origine missionnaire entraîna la désintégration sociale des Chasutas et accéléra ainsi les processus mis en place par le boom du caoutchouc.

Mots clés : Indiens amazoniens, peuples indigènes, Chasutas, Amazonie, Loreto, Huallaga, Mainas, missions, soulèvements, citoyenneté ethnique.

\section{CHANGES AND CONTINUITIES IN THE COLONIAL PACT IN AMAZONIA. THE CASE OF CHASUTA AT THE END OF 19 ${ }^{\mathrm{TH}}$ CENTURY}

\section{Abstract}

This article explains the occurrence of an uprising in Chasuta in 1893 as the result of what local Indians perceived as the infringement of the colonial pact that guarantied their rights and

\footnotetext{
*E-mail: barclay.f@pucp.edu.pe
} 
stipulated their duties vis à vis the local administration. It suggests that the dissolution of such a pact led to the social disintegration of the Chasuta as a people and that it accelerated those processes driven by the rubber boom.

Key words: Amazonian Amerindians, Indigenous peoples, Chasuta, Amazonia, Loreto, Huallaga valley, Mainas, Missions, Uprising, Ethnic Citizenship.

En el tránsito del orden colonial al republicano la definición de la forma de gobierno y organización política de la población y el territorio fue uno de los asuntos de importancia central ( $c f$. Contreras \& Cueto, 1999: 34). Dado que en el contexto de la ideología liberal que daba sustento al nuevo régimen político no era dable pensar las nuevas repúblicas sin que sus habitantes adquirieran la condición de ciudadanos, desde la perspectiva de los constructores de los nuevos estados tal definición pasaba, a su vez, por establecer los marcos jurídicos para la constitución de ciudadanos y la integración de todos sus habitantes a la vida política y económica de la nación.

En los países andinos, la integración de la población indígena a la vida política y económica de la nación resultaba un punto crucial en la medida que ésta era mayoritaria. De ahí que en el Perú se adoptaran tempranamente medidas en ese sentido aunque éstas tuvieran un efecto muy atenuado o fueran eventualmente revertidas. En esta línea se encuentran la supresión del tributo indígena, la extinción de la propiedad corporativa, la abolición de los cacicazgos, la extinción de la Caja de Censos de Indios, y la supresión del uso legal de los términos "indio" y "natural".

El intento de abolir la propiedad colectiva respondía a la noción de conformar los derechos y deberes de los indígenas con los de los criollos, blancos y mestizos, entendiéndose como una condición del ejercicio de la ciudadanía la propiedad individual de las tierras. La supresión de los cacicazgos, en cambio, procuraba asegurar el establecimiento de lealtades directas para con el Estado sin la mediación de tales operadores coloniales. Sin embargo, el propósito filosófico-político de fondo de éstas y las otras medidas era, como se sabe, la reforma del régimen de corporaciones o castas. A la base de este régimen, estaba la idea de que la sociedad estaba constituida por agrupaciones o cuerpos sociales. Además, la ubicación en la jerarquía social, los derechos y obligaciones de los individuos venían definidos por su afiliación natural o pertenencia a alguno de estos cuerpos. En el caso de los indígenas, los cuales llegaron a ser concebidos como integrando una "república" al interior del espacio sociopolítico colonial, el "derecho indígena" establecía su condición de tutelados y los sometía a un régimen de protección. La pervivencia de estos cuerpos, que no empataba con la noción de individuos iguales ante la ley, contradecía la idea liberal de una república constituida por ciudadanos.

Dicha reforma jurídica no llegó a plasmarse plenamente porque el ordenamiento económico exigía que la fuerza de trabajo indígena, mayoritaria y fundamental para su funcionamiento, pudiera seguir siendo controlada y movilizada mediante mecanismos políticos e ideológicos. Además, en el marco de este ordenamiento, la igualdad legal de los indígenas suponía el riesgo de que, librados de su condición de tutelados, quedaran expuestos a aún mayores abusos. No obstante, a lo largo del siglo XIX se introdujeron 


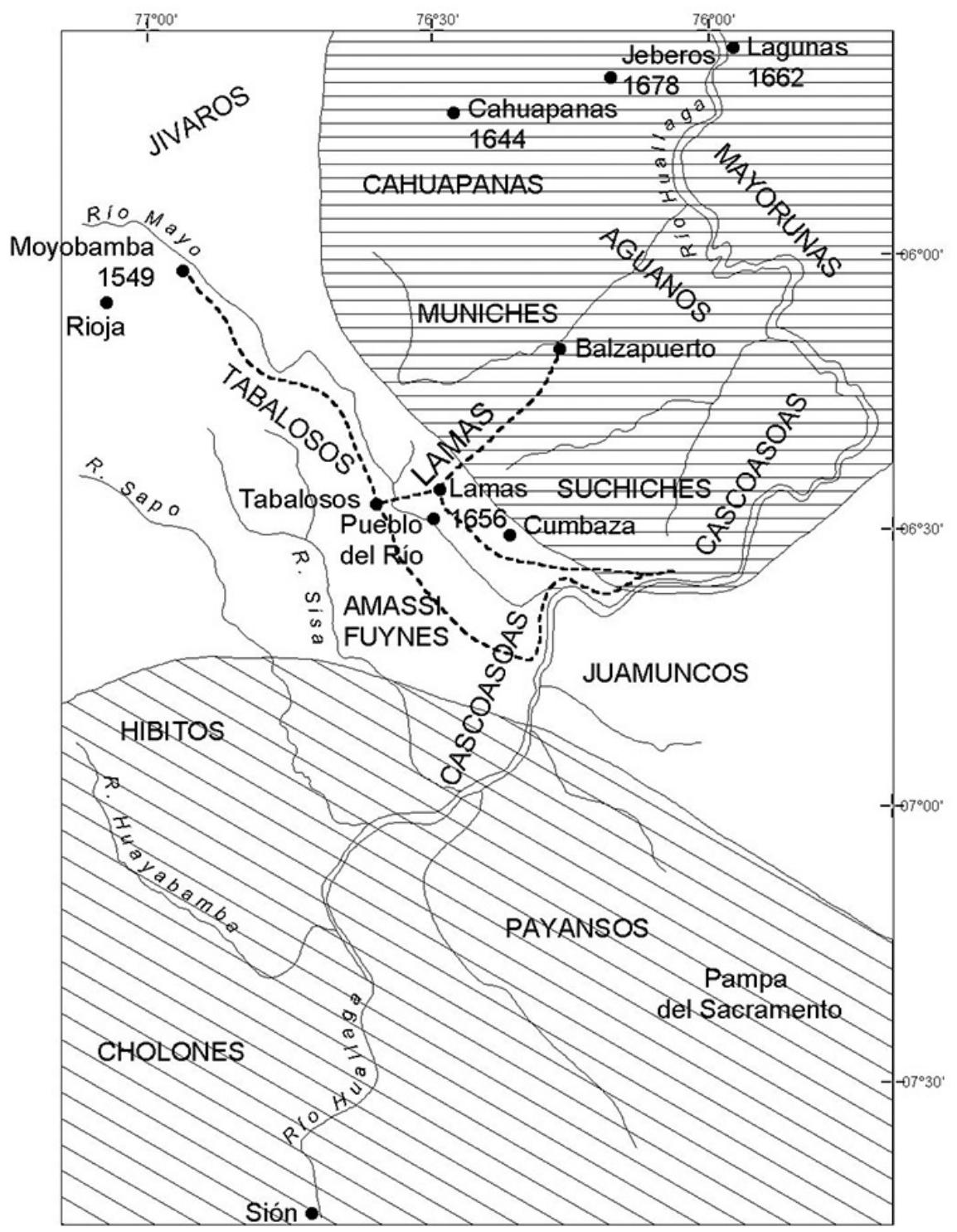

\section{LÍMITES DE LOS TERRITORIOS MISIONALES}

\section{LEYENDA}

$\Longrightarrow$ Misiones Jesuitas

$\square$ Misiones Franciscanas

Rutas seguidas por Riba Herrera

Fig. 1 - Límites de los territorios misionales (Scazzochio, 1981: 105). 
pobreza" (Velasco, 1789: XVI, 329, citado por Scazzocchio, 1981: 107), la existencia de importantes minas de sal resultaba fundamental para el control del espacio misional de Mainas. En esa medida, el desarrollo de las misiones del Huallaga central, conectadas al Marañón y sus afluentes septentrionales a través de las misiones de Balsapuerto, Xeveros y Cahuapanas y al Amazonas y Napo a través de la ruta fluvial, pasó a ser una pieza fundamental del esquema misional y de su circuito de intercambio. En efecto, aparte de la sal, esta zona proveía a las misiones de Mainas de tejidos de algodón y de veneno de Lamas, también llamado curare. Además, las misiones establecidas en el Huallaga central delimitaban la frontera sur del espacio jesuita separándolo de aquel controlado por los franciscanos.

Como lo señala Scazzocchio (1981: 107) la misión de Lamas instauró una diferenciación fundamental entre indígenas "catequizados" ("civilizados", "semicivilizados") e indígenas "bravos" ("salvajes") que pasó a ser la base de un sistema de clasificación de la población que se mantuvo vigente hasta bien entrado el siglo XX. Las normas establecidas por los jesuitas para los pueblos reducidos en estas misiones fueron la base de una cultura misional de fuerte arraigo en la región con su calendario de festividades religiosas, su estilo de vestimenta y comidas (con el uso de sal en las comidas que se convirtió en un rasgo diacrítico de la población catequizada o semicivilizada), patrones de producción y el empleo del quechua o inga como lengua común.

Como en otras zonas, las misiones jesuitas redujeron a distintos pueblos obligándolos a la convivencia, aunque formando dentro de las misiones "barrios" para cada uno de ellos. Entre estos pueblos están aquellos citados como las seis naciones reducidas en torno a Lamas. Sin embargo, el panorama étnico precolonial de esta región es poco claro. Aparte de las populares teorías de un origen andino (chanca) para la población misionarizada de la zona, existe poca certeza acerca de la naturaleza de los conglomerados o "naciones" de la región. Mientras que los tabalosos, lamas y suchichis parecían hablar un mismo idioma o dialectos de un idioma común, otros como los juamucos y amaysifunes parecen haber hablado lenguas o dialectos de lenguas distintas.

Al mismo tiempo, mientras las reducciones misionales terminaron imponiendo la convivencia de algunos (lamas y amaysifunes, por ejemplo), convirtiéndolos en cuasi-linajes de una misma entidad étnica, en otros casos los que pueden haber sido clanes o linajes de un mismo pueblo terminaron convertidos en conglomerados diferenciados en virtud de su reducción en aldeas separadas (posiblemente los tabalosos respecto de los lamas) (2). En efecto, aunque mucha de la población mantuvo un patrón espacial de ocupación disperso, toda la población rural pasó a estar adscrita a un centro "urbano" en particular, donde estaban censados, para cumplir con sus obligaciones de trabajo, participar en fiestas y contribuir al mantenimiento de sus capillas y "alhajas". Los poblados tomaron los nombres de las "naciones" principales allí reducidas y a la vez, toda la población de su ámbito de influencia pasó a responder a ese gentilicio común

(2) Espinosa Pérez (1955, I: 579), refiriéndose a los tabalosos, motilones y calzas blancas, estima que se trataba de "parcialidades de un mismo pueblo con cierta independencia tribual". Y se refiere a los indios contemporáneos de los pueblos de Tabalosos, Lamas y otros inmediatos como Chasuta, como "restos de los indios dichos". Tessmann (1999: 128-136), a su vez, distingue a los Lamisto de los Chasutino. 
sin que éste hubiera sido necesariamente su referente étnico original (3). Cada uno de estos pueblos con sus calendarios y tradiciones pasó a ocupar una posición y una especialidad en el cuerpo constituido por las misiones, el de los indios catequizados quechua hablantes.

Tras la expulsión de los jesuitas en 1767, la zona de Lamas y Moyobamba pasó a depender del Obispado de Trujillo. Sin embargo, como en otras zonas, el clero secular destinado a las antiguas misiones de Mainas mantuvo las prácticas misionales locales bien establecidas, de manera que no obstante la desarticulación del circuito misional, y la intervención de clero secular y de otras órdenes, elementos importantes del sistema puesto en práctica por los jesuitas mantuvieron su vigencia: el sistema de turnos y calendario festivo, la adscripción y referencia a centros poblados y capillas locales y los criterios de clasificación de esta población "semi-civilizada". Bajo un aire general cada uno de estos pueblos en el doble sentido de localidad y de colectividad indígenas desarrolló un estilo particular de cerámica, vestido, formas de realización de sus fiestas patronales, etc (4).

Algunos de estos elementos estaban a la base de ciertos "pactos" con las autoridades. Y aunque éstos no estaban sancionados por ningún documento, y eran sólo parte de "la costumbre", para los indígenas, tenían el carácter de derecho adquirido (5). A su vez, estos elementos eran la base de su condición como "ciudadanos misionales" (oétnicos). Si bien puede argumentarse que algunos o muchos de estos elementos fueron usados para ventaja de los comerciantes y propietarios de tierras locales, como lo demuestra el episodio que aquí se analizará, a fines del siglo XIX los indígenas todavía esperaban que dichos pactos — que les daban un margen de acción como indios catequizados - fueran respetados y, cuando no sucedía así, estaban dispuestos a protestar con toda energía.

\section{LOS CHASUTAS Y LOS CAMBIOS Y CONTINUIDADES ENELSISTEMA MISIONAL TRAS LA INDEPENDENCIA, 1821-1860}

Los indígenas que en el siglo XIX eran conocidos como chasutas parecen ser los mismos que en el siglo XVII eran llamados "cascabosoas" (6). Si el gentilicio temprano

(3) Más adelante, y progresivamente, los gentilicios fueron convirtiéndose en apellidos de la misma denominación. Asimismo, conforme avanzó en el siglo XX el proceso de "desindigenización", algunos de estos gentilicios-apellidos fueron "traducidos" en apellidos de origen castizo de modo que, por ejemplo, los Tabalosos se hicieron Salas en un intento por escapar al sistema de clasificación estamental ya resquebrajado que asociaba los apellidos étnicos con la noción de "apellidos bajos". Para un análisis del surgimiento del estrato ribereño en la región que corresponde a la antigua Mainas ver Santos Granero \& Barclay, 2000.

(4) Lo que a ojos de un foráneo son costumbres y prácticas casi idénticas, para los lugareños son marcadores clarísimos de origen y pertenencia. En varios de estos pueblos en lo que sus habitantes han renunciado a una identidad "indígena" la afirmación de una identidad local es todavía de gran importancia.

(5) Los documentos de la época no hacen referencia al criterio vigente en otras zonas de misión de clasificar a los indios como "indios libres", es decir aquellos empadronados en un poblado para la realización de turnos y reservados para servicios públicos (Muratorio, 1987; Barclay, 1998).

(6) En las fuentes jesuitas también se los llama churutinas (Figueroa et al., 1986: 238). 
responde probablemente a una denominación castellanizada originalmente dada a este pueblo (¿o linaje?) por alguno de sus vecinos, el de chasutas responde a la lógica de nombrar a los habitantes de una región por el de su centro poblado misional de referencia. En efecto, en el siglo XVIII Chasuta era uno de los núcleos misionales del Huallaga medio junto con otros como Lamas (Fig. 2), Tabalosos, Shapaja, San José de Sisa y Saposoa.

El poblado de Chasuta tomaba ventaja del hecho de hallarse ubicado en un terreno de altura en la margen izquierda del río Huallaga, al sur de Yurimaguas, no lejos de la desembocadura del río Mayo, al pie de una de las más importante minas de sal (Fig. 3). Además, estaba ubicado en un punto a partir del cual, aguas arriba, se dificultaba la navegación del río Huallaga debido a la existencia de varios peligrosos "pongos" (7). De ahí que los chasutas se hubieran especializado en el transporte fluvial al frente de balsas y canoas. Chasuta ofrecía además una ruta de comunicación menos exigente para el traslado de carga por río y trocha hacia Tarapoto y Lamas y de ahí a la costa. Acentuando aún más la importancia logística de esta localidad estaba el hecho de que frente a ella se encontraba la desembocadura del río Chipurana que comunicaba con el río Yanayacu y por medio de éste con el Ucayali (8).

Aunque existe muy poca información acerca de esta región para los primeros años de la vida republicana, tres décadas más tarde una serie de viajeros dejaron informes de su estadía en ella. A juzgar por los informes de W.L. Herndon (1991: 231) quien visitó Chasuta en 1851, de R. Spruce quien recorrió la región entre 1855 y 1857 y de A. Raimondi (1940: 110 ; 1942: 57) quien realizó sendos viajes en 1858 y 1869, una serie de cambios parecían haber mellado el ordenamiento creado por el sistema misional.

Entre los factores de cambio recientes estaban los derivados del establecimiento de la navegación a vapor. Gracias a ésta el poblado de Tarapoto se estaba convirtiendo rápidamente en el centro de comercio de la producción de sombreros de paja toquilla, zarzaparrila y tabaco del alto Amazonas que era trasladada hasta Nauta por el Huallaga y el Marañón para ser exportada a Belén de Pará. Los vapores, que inicialmente llegaban sólo hasta Nauta, empezaron a surcar el Huallaga hasta el puerto de Yurimaguas. Desde allí, la carga debía ser trasladada hacia Tarapoto por alguna de dos vías. Un camino permitía trasladarse de Yurimaguas a Tarapoto atravesando las altas montañas que separan a estas dos ciudades. Este penoso camino requería de un gran número de cargadores, siempre difíciles de conseguir. La otra opción era surcar el río Huallaga en canoa hasta Chasuta, ahorrando gran esfuerzo. A partir de allí, se podía tomar un camino menos farragoso hacia Tarapoto o, cuando el río no estaba demasiado crecido, seguir surcando hacia Shapaja en la desembocadura del río Mayo, lo que exigía que los bogas chasutas transbordaran la carga en los malos pasos conocidos como pongos. De ahí que

(7) Esta ubicación como otras al pie de un pongo hacía que año a año, en cada período estival se presentara el fenómeno del "mijano" (las migraciones de peces aguas arriba de los ríos amazónicos) convocando a la pesca a propios y ajenos: el estrechamiento del río provoca que los peces que migran aguas arriba se entrampen intentando cursar el pongo, lo que facilita su pesca.

(8) Es por ello que hasta fines del siglo XIX la región del Ucayali pertenecía a la provincia de Alto Amazonas y más adelante a la de San Martín. 


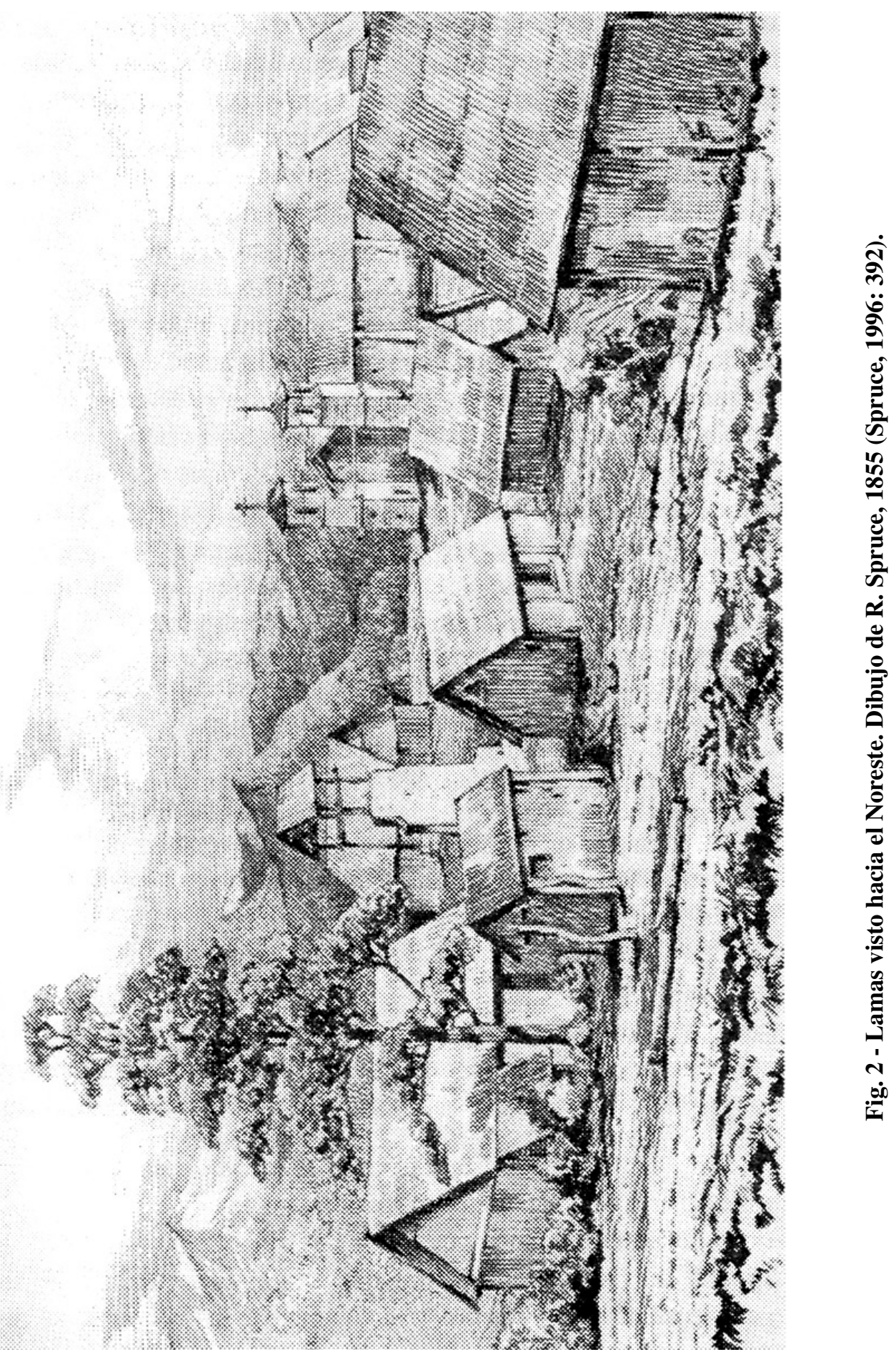




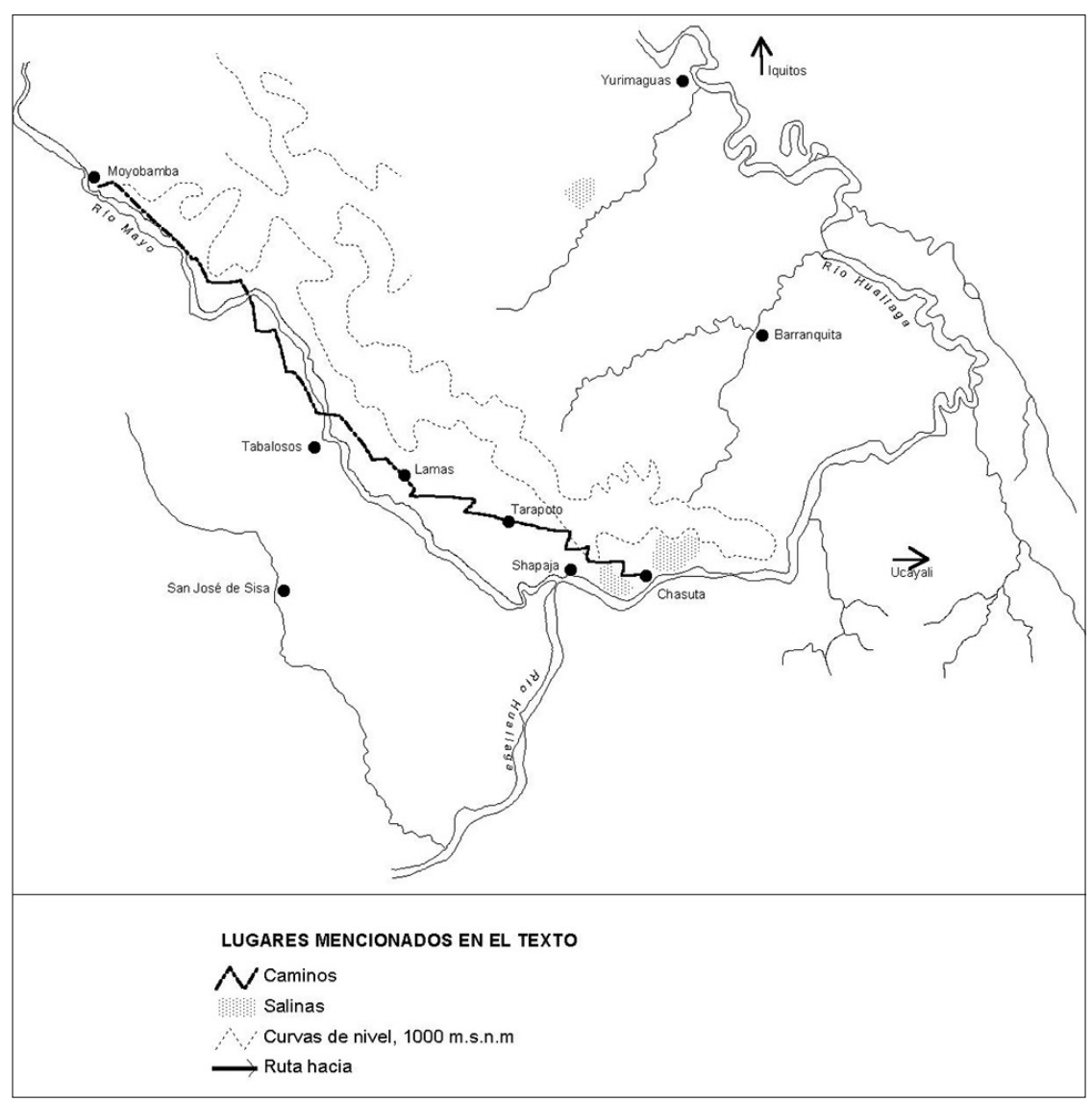

Fig. 3 - Lugares mencionados en el texto.

aunque Chasuta no se hubiera constituido en un centro de comercio o producción para la exportación de alguna significación, el poblado y sus habitantes indígenas habían retenido cierta importancia para la administración y el comercio de la región.

Los habitantes de Chasuta estaban dedicados a actividades agrícolas de subsistencia en sus propios terrenos. Además, siguiendo una práctica misional, los hombres se dedicaban a la recolección de cera de abeja para la elaboración de velas. Las mujeres empleaban su tiempo en hilar y tejer; según reportan los viajeros, ovillos y tocuyo, junto con la cera de abeja, eran los principales medios de intercambio a su disposición con los que podían pagar al cura sus servicios y pagar el "camairico" (9).

(9) En el marco de las misiones jesuitas el camairico era una obligación colectiva debida a los misioneros por sus catecúmenos en forma de bienes. Aparentemente cada misión establecía el concepto de la obligación, el cual podía incluir la entrega de oro de los lavaderos aluviales. El camairico también se pagaba con pescado y productos agrícolas para el consumo del misionero (Figueroa et al., 1986: 202). 
La situación descrita por estos viajeros permite apreciar ya entonces un cuadro mixto de transformaciones y continuidades en Chasuta. En 1853 el poblado de Chasuta tenía una población de 1008 habitantes, pero como reportaba Raimondi (1942: 56) ésta se encontraba en aumento (aproximadamente 1500 en 1869). Spruce (1996: 372) informaba que toda la población era indígena "aunque muchos dejan ver rasgos evidentes de sangre blanca". Así, aunque ya no existía una estructura misional, la sumisión al cura y rituales cotidianos de antaño seguían vigentes como lo atestigua el hecho de que se le saludaba arrodillándose y besándole la mano (Herndon, 1991: 231). Además, por turnos los indígenas seguían obligados a prestar servicios al cura, pedido que debía hacer el gobernador de Chasuta a las autoridades locales, el alcalde y sus fiscales. Estos últimos continuaban siendo elegidos anualmente para organizar los turnos de trabajo y mantener el orden. Spruce (1996: 372) reportó que, en la época de su visita, en Chasuta el gobernador era un indígena anciano que hablaba algún castellano por haber sido soldado.

Entre los cambios ocurridos resaltan aquellos relacionados con la administración política, económica y territorial del antiguo espacio colonial misional. Estos cambios provenían principalmente de la imposición, por parte del nuevo orden estatal, de una estructura administrativa y política. Para comenzar, habían ocurrido cambios importantes a nivel de la delimitación de la circunscripciones territoriales. Los nuevos distritos y la provincias del alto Amazonas contaban ahora con autoridades no indígenas y ajenas al sistema misional, las que presionaban a las autoridades indígenas locales (gobernador y alcalde), subordinadas al gobernador del distrito de Tarapoto, pronto convertido en provincia con el nombre de San Martín (10). Este progresivo avance del Estado es el contexto en el que la administración étnica es dejada de lado y el pacto colonial abandonado.

A su vez, las nuevas autoridades al frente del sistema de administración étnica eran piezas de una nueva estructura de poder local. Este sistema se basaba tanto en ciertas tradiciones de origen misional cuanto en la necesidad, poco diferenciada de satisfacer intereses propios con tareas estatales (Guerrero, 1993: 91). Aunque la figura de los gobernadores locales indígenas fue mantenida hasta fines del XIX, ésta se fue debilitando al punto de que el cargo empezó a ser ocupado por afuerinos. Cabe señalar que los gobernadores indígenas que eran pieza importante del sistema tradicional misional, tenían autoridad sobre los habitantes locales, los indígenas chasuta, y no sobre una circunscripción territorial de modo que no podía imponer sanciones a los comerciantes blancos ni incluso sobre otros indígenas que se encontraran en la localidad.

Para la década de 1850 el Gobernador del distrito de Tarapoto demandaba de las autoridades indígenas locales la organización de turnos para atender las necesidades de la administración local. Un decreto de 1825, reiterado en 1867, prohibía el trabajo

(10) Hasta 1857 Loreto era una gobernación política del departamento de Amazonas. Ese año fue creada la provincia litoral con capital en Moyobamba y 10 distritos, uno de los cuales era el de Tarapoto. En 1861 el Departamento Marítimo Militar de Loreto, ratificado como departamento en 1869, aún con capital en Moyobamba, pasó a tener dos provincias (Alto y Bajo Amazonas) al interior de los cuales se crearon distritos. Chasuta, que había pertenecido al distrito de Tarapoto pasó a ser primero parte de la Provincia de Huallaga y más delante de la de San Martín, con capital en Tarapoto. 
forzado de los indígenas, las contribuciones en productos exigidas a éstos por las autoridades y la realización de servicios a favor de las autoridades sin mediar el pago anticipado de los jornales (11). No obstante, como una ley de 1832 había establecido la exención de impuestos para los habitantes de la región para fomentar su colonización, las contribuciones indígenas en trabajo y especies eran la fuente principal para financiar los gastos de la administración local y regional.

Por disposición del gobierno central las autoridades civiles tenían la obligación de supervisar la celebración de contratos de prestación de servicios en los que intervinieran indígenas, asegurando su pago por adelantado y en efectivo. En el caso de los chasutas, sabemos que estos servicios particulares se referían fundamentalmente al trabajo como bogas (12). Herndon (1991), quien tuvo que negociar con el gobernador de Tarapoto la contratación de cargadores y bogas indígenas, señalaba con suspicacia que dudaba que los jornales entregados a esta autoridad llegaran a manos de los indígenas. Aunque sabemos que los propietarios de tierras y comerciantes locales de la región dedicados a la producción de tabaco y a la extracción de zarzaparrilla empleaban peones indígenas, no existe información acerca de si los chasutas eran empleados en estas tareas y bajo qué condiciones. Sin embargo, parece cierto que los chasutas retuvieron sus tierras, lo que no excluye que fueran habilitados y contratados por jornales (13).

Otro indicador del cambio social está asociado a las constantes borracheras reportadas tanto por Raimondi (1940: 110) como por Herndon (1991: 231). Si bien el consumo de jugo y guarapo de caña era tradicional al espacio misional, el hecho de que ambos viajeros hicieran hincapié en su inclinación a la bebida y a su interferencia con la prestación de servicios indica tanto que el habitus misional se había resquebrajado, cuanto que los chasutas — como otros indios de misión - se encontraban en una situación de resistencia pacífica (Muratorio, 1987: 27-44). No obstante las quejas de ambos viajeros respecto de la dificultad para reclutarlos como bogas y cargadores, Herndon (1991: 231) retrató a los indios de Chasuta como "una raza dócil y tranquila y obedientes con su sacerdote".

(11) Ver Mattos (1984: 67-8). En su artículo 1 el decreto del 4 de julio de 1825 mandaba que ninguna persona exija directa o indirectamente servicio personal a los indios sin que antes se hubiera firmado un contrato libre sobre el precio de su trabajo; el art. 2 prohibía a las autoridades locales (civiles, militares y eclesiásticas), así como a mineros y hacendados a emplear indios en contra de sus voluntades. En 1864 el gobierno reiteró esta obligación enviando una circular a los gobernadores para que éstos impidieran la comisión de abusos. Así y todo en 1867 , fue necesario expedir un nuevo decreto del 28 de agosto ordenando se diese estricto cumplimiento a lo establecido por el decreto de 1825 .

(12) Raimondi fue enfático en su descripción de la destreza de los chasutas como bogas al describir las dificultades de navegación en el tramo de Shapaja a Chasuta y de ahí a Yurimaguas (Raimondi, 1942: 299-300).

(13) En su Diccionario topográfico de Loreto de 1874 de Mattos (1984: 18) señalaba que los "Chassutinos" son activos y están dedicados a la pequeña producción y al cultivo de caña de la que fabrican aguardiente y añade que en el poblado de Chasuta existe una escuela primaria para niños varones. No sabemos sin embargo si a esta escuela asistían los niños indígenas o si las referencias a la producción se refieren a éstos o a los patrones no indígenas establecidos en la localidad. 


\section{ELHUALLAGA CENTRALEN ELDESARROLLODEL AUGEGOMERO, 1860-1893}

Pocos años después de la visita de Herndon, Spruce y Raimondi a Chasuta el departamento de Loreto, al que pertenecía la región del Huallaga central, entró en un acelerado proceso de cambio debido al auge de exportación de gomas. Tarapoto fue perdiendo su importancia como centro de gravitación del comercio a medida que el eje de producción y comercio se desplazaba hacia el este. Mientras que los cambios producidos en la porción occidental del departamento de Loreto son bastante conocidos (San Román, 1975; Stocks, 1981; Santos Granero \& Barclay, 2000), poco se sabe acerca de los reacomodos que debieron ocurrir en esta última zona.

En términos generales, sabemos que a consecuencia del incremento en los precios de las gomas, la región que anteriormente había correspondido a la Misión Alta, había sufrido los efectos de un marcado despoblamiento. La densa red de antiguos centros misionales de la cuenca del Huallaga fue, junto con las misiones el alto Marañón y bajo Huallaga, la principal fuente de mano de obra en las primeras fases del ciclo cauchero. Diversos documentos de fines del siglo XIX dan cuenta de esta masiva migración, principalmente masculina y de los métodos de reclutamiento de esta población. Aunque muchos patrones-comerciantes del Huallaga marcharon con sus peones hacia las zonas de extracción cauchera, el desplazamiento de la mano de obra indígena "civilizada" debió haber afectado a los propietarios y comerciantes que permanecieron en la zona.

De igual forma debió haberles afectado el hecho de que Moyobamba, entonces todavía la capital del departamento de Loreto hubiera perdido su importancia como centro político de la región justo en el momento en que la reforma descentralista de 1887 daba a los departamentos mayor autonomía en la aplicación de los presupuestos y rentas fiscales. Aunque la capital del departamento no fue formalmente trasladada a Iquitos sino en 1897, desde mediados de la década anterior el Prefecto había establecido su residencia en ese puerto (14). De ahí que durante ese período las autoridades de la región y sus representantes al Congreso, oriundos del Huallaga, demandaran insistentemente la restitución de la sede y la asignación de mayores recursos a las provincias altas (15).

Uno de los argumentos esgrimidos para reclamar el retorno de la máxima autoridad a Moyobamba y los mayores recursos fue la necesidad de hacer frente a motines y levantamientos indígenas que intranquilizaban a los pobladores blanco-

(14) El prefecto Rivera restableció brevemente la sede de la Prefectura en Moyobamba entre 1890 y 1893. El entonces distrito de Tarapoto que pasó a ser la provincia de San Martín del departamento de Loreto, es hoy en día provincia de un departamento distinto, el de San Martín. Ver AGN 1890-1893. Prefectura. Legajos 15, 18, 21, 23, 24, 33). Martínez Riaza (1999: 422) considera al prefecto Rivera una de la autoridades que favorecieron el establecimiento de la capital en Iquitos, argumentando que la "vigilancia de los intereses de la nación" sólo podía ser ejercida en esa ciudad.

(15) AGN 1887. Prefectura, Legajo 5. Oficio del Senador por Loreto, Jerónimo Lama al Ministerio de Gobierno y Obras Públicas. 18/05/1887; AGN 1887. Prefecturas, Legajo 5. Oficio del Senador Gerónimo Lama al Ministro de Gobierno referida a disposición prefectural del Gral. Velarde. 18/05/1887; AGN 1889. Prefecturas, Legajo 11. Oficio de los Diputados Juan del Aguila, Pedro Secada, Eduardo Raigada y Jerónimo San Martín al Ministro de Gobierno. 16/08/1889. 
mestizos y autoridades locales. En efecto, en 1887 el subprefecto del Cercado de Moyobamba, dirigiéndose al Director General de Gobierno en Lima, para protestar por el hecho de que el recientemente nombrado Prefecto había viajado a Iquitos "sin siquiera haber visitado esta capital" y demandar la necesidad de un mayor número de gendarmes, daba cuenta de un grave motín protagonizado por los indígenas de San José de Sisa en marzo de ese año (AGN 1887. Prefectura, Legajo 5. Oficio del Subprefecto del Cercado de Moyobamba, Pablo Mori al Director General de Gobierno. 23/04/1887). En un oficio, el gobernador del distrito le había informado que "los motinistas" indígenas habían dado muerte a dos personas y quemado dos casas y que no dejaban pasar hacia arriba a Saposoa ni hacia abajo a Lamas, amenazando de muerte a quienes lo intentaran (AGN 1887. Prefecturas, Legajo 5. Oficio del Gobernador de San José de Sisa, Abel Tuesta al Subprefecto del Cercado de Moyobamba, Pablo Mori. 27/03/1887). Informaba también acerca de sus infructuosos intentos por conseguir el auxilio del subprefecto de San Martín, al que pertenecían tanto San José de Sisa como Chasuta, lamentándose de que no hubiera en la zona "gente blanca de quien valerse y moralizar con ellos el lugar".

Aunque no se informa el motivo de este motín, podemos suponer que el localizado levantamiento pudo haber tenido que ver con el desconocimiento por parte de las autoridades locales de alguna de las costumbres instauradas en el marco del régimen de las misiones (16). Si bien con esta denuncia el Subprefecto de Moyobamba pretendía llamar la atención de las autoridades centrales acerca de la poca atención prestada a la región, éste y las autoridades de Lima — quienes ordenaron "reprimir los delitos cometidos por los indígenas"- estaban conscientes del peligro que podía significar un levantamiento general de los indígenas "semi-civilizados" del Huallaga. Entre otros peligros estaba el de que se interrumpiera la más directa comunicación con el resto del país y la capital por vía de Tarapoto, Lamas y Moyobamba. Precisamente las medidas tomadas para mantener transitable esta vía —a la que informes de 1889 acerca de la hostilidad de Manaos contra el comercio peruano de gomas obligaban a prestar mayor atención - fue el detonante del levantamiento de Chasuta ocurrido en 1893.

4. LOS ACONTECIMIENTOS DE CHASUTA DEL 10 DE JULIO DE 1893 (17)

Un carta del comerciante, gobernador del distrito delCercado y anterior gobernador de Chasuta, Pablo Díaz, del 12 de julio de 1893, alertaba al subprefecto del cercado de

(16) En este caso no tenemos información acerca de qué produjo el motín de San José de Sisa. Basadre (1964: Tomo VI, 2792) reporta varios levantamientos en zonas serranas ocurridos en la sierra entre 1887 y 1892 contra la aplicación de la contribución personal. Estos levantamientos antifiscales en las zonas andinas tenían como contexto el Segundo Militarismo tras la Guerra del Pacífico en el marco del cual se desarrolló una política contradictoria con relación a los indígenas con quienes Cáceres había establecido una suerte de pacto (Núria Sala i Vila, comunicación personal). Los levantamientos en contra de los gravámenes que pesaban sobre los indígenas, también ejercían una protesta contra la ruptura de un pacto, recordando en última instancia que el pacto tenía el beneficio de la "gobernabilidad".

(17) Esta sección se basa fundamentalmente en documentación del Archivo General de la Nación (AGN) del fondo de Prefecturas. 
Moyobamba, acerca de un levantamiento ocurrido dos días antes en la localidad de Chasuta y de la muerte del subprefecto de la provincia San Martín a manos de éstos. La misma añadía que la suerte del gobernador y el cura conversor de Chasuta eran incierta y que la "actitud salvaje de los Chasutinos" había resultado en la interrupción de la comunicación entre los distritos (AGN 1893. Prefecturas, Legajo 33. 1893. Carta del Pablo Díaz al Subprefecto de San Martín. 12/07/1893). La noticia, que no tardó en llegar al prefecto Rivera que se hallaba en Iquitos, hizo que éste se pusiera en camino hacia Chasuta, en agosto de ese mismo año, al frente de 25 gendarmes.

Para reconstruir los acontecimientos contamos con una profusa correspondencia cruzada entre el gobernador de Chasuta, Emilio Sandoval, el gobernador de Tarapoto y subprefecto accidental, Pablo Díaz, el Concejo Provincial de Tarapoto, y el gobernador del Cercado de Moyobamba, el subprefecto de Alto Amazonas, el prefecto de Loreto y el Director General de Gobierno en Lima entre el 12 de julio y el 28 de agosto de 1893 (AGN 1893. Prefecturas, Legajos 33 y 37).

Según las mismas, el recientemente designado subprefecto de San Martín (18), don José Abel Bello, "queriendo mostrar" su decisión de acción y su empeño en relación al mantenimiento del camino a Tarapoto, había llegado a Chasuta el día 6 de julio acompañado de 4 gendarmes y algunos policías. Desde Rumicuchi había anunciado al gobernador Sandoval el propósito de su visita y apenas llegado ordenó por intermedio éste la salida de una partida de 12 cargueros que debía conducir los víveres y materiales, la misma que arribó de regreso a Chasuta el día 8. El domingo 9, Bello pasó revista a los 160 pobladores que debían realizar los trabajos de reparación del camino y mandó que se constituyeran en dos comisiones. La primera, al mando del teniente gobernador indígena Gualberto Tanchiba, debía encargarse del tramo comprendido entre el canto del pueblo y Purma Ashpishca; la segunda, al mando del juez de paz Aniceto Shashnamote, también indígena, debía ocuparse del tramo desde Pucayacu hasta la punta del cerro Huaira-Purina.

El día designado para el inicio de los trabajos, las autoridades locales informaron que la gente llegaría hacia el medio día pues debían caminar desde sus chacras. Para esa hora, el gobernador Sandoval ya tenía indicios de que la gente, que llegaba en grupos hacia la plaza, venía con los ánimos caldeados. Estando todo el pueblo reunido, con gran "vocinglería" los indígenas reclamaron al Subprefecto les entregara hachas y machetes, diciéndole que "el Estado debía haberle mandado". Como respuesta a este pedido, "con gran sagacidad" (?) Bello les habría entregado seis hachas indicándoles que era "el vecindario de Tarapoto" quien donaba las herramientas y los víveres (19). El Subprefecto les indicó asimismo que los víveres les serían entregados en el camino.

(18) Bello había sido nombrado en abril de 1893. Una referencia a la renuncia en 1892 del anterior subprefecto, Pedro Reátegui, nos da una indicación acerca de que, pese a que la región del Huallaga no gozaba de todos los beneficios de la bonanza del Bajo Amazonas, el grupo de comerciantes que controlaba los puestos políticos gozaban de una buena situación. Al renunciar a su cargo por motivos de salud, indicaba que esperaba recuperarse en Iquitos y que si no pasaría a Europa ... (AGN 1892. Prefecturas, Legajo 29. Oficio de renuncia del Subprefecto de San Martín al Prefecto de Loreto. 20/09/1892).

(19) Este dato resulta curioso en la medida en que, al menos el presupuesto del Concejo Provincial del Cercado de Moyobamba de 1896-97 votaba recursos para el "reparo del camino 
En sus varios informes a las autoridades, Sandoval informa que a poco de iniciada la marcha de las comisiones, se presentaron "los encargados" indicando que les habían sido arrebatados los víveres junto con dos garrafones de aguardiente, sin dejar nada para entregar en el camino. Para poner orden, el Subprefecto, acompañado del gobernador, sus gendarmes y algunos alcaldes indígenas, se dirigió hacia donde se encontraba la segunda de las comisiones. Al llegar al río, los indígenas les habrían cerraron el paso y, blandiendo los machetes, le cortaron el hocico a la mula en que Bello iba montado. Otras versiones, indican que ante la negativa de parte de los indígenas a realizar el trabajo y los "insultos" proferidos contra el Subprefecto, éste intentó castigarlos y poner en cepos a los cabecillas, a lo cual reaccionaron con gritos y dando planazos y machetazos a los gendarmes que empuñaban sus sables y los rejoneaban con sus lanzas. Según la versión de Sandoval, para ese momento los gendarmes que habrían hecho tiros al aire, dejaron escapar un tiro o apuntaron sus escopetas hacia el grupo sublevado, matando al teniente gobernador Tanchiba y enardeciendo aún más el ánimo de los indígenas.

En ese contexto, uno de los gendarmes de Bello fue capturado por los indígenas quienes lo hubieran ahogado de no ser por la intervención de Sandoval quien de inmediato lo llevó a la Casa Conventual. Mientras el gobernador se hallaba en el convento, Bello y sus tres guardias se refugiaron en la casa de Sandoval desde donde se defendieron con armas de fuego. Poco después, sin embargo, sus atacantes prendieron fuego al techo de hojas de palma. Enterado del fuego en su casa, el gobernador Sandoval se dirigió a su casa en llamas pero en el camino fue rodeado por un grupo de indígenas quienes lo acusaron de ser responsable por "haber llamado al Subprefecto" [para organizar el trabajo de reparación del camino] y lo golpearon a planazo. La intervención de su mujer e hijos, aparentemente indígenas, permitió que escapara hacia el monte donde se refugió tres días.

Entre tanto Bello y sus tres gendarmes habían logrado huir por atrás hacia el puerto donde abordaron una canoa que recién arribaba. Un indio, Bernabé Chisquipama, intentó detenerlos pero fue herido y quedó tendido en la playa. Al darse cuenta de la huida de Bello y sus soldados, los chasutas los siguieron por río hasta Santa Cruz donde, expertos remeros, le dieron alcance y los mataron. La cabeza de Bello fue llevada a la plaza "para que la coman los perros", al tiempo que se amenazaba a aquellos que intentaran enterrar a los muertos.

Esa misma tarde, el gendarme refugiado en la casa del cura intentó escapar y en su huida mató de un tiro al indio Cecilio Chasnamote. Al ser capturado le cortaron la cabeza y llevaron su cuerpo a la plaza donde le dieron vueltas hasta dejar el cadáver en la puerta de la Iglesia. El cuerpo que el cura mandó sepultar fue luego desenterrado por una turba para echarlo al río. El gobernador, que había huido al monte fue perseguido por los alrededores por grupos de hombres que hacían "alarde de sus crímenes" impidiéndole reportar los hechos a las autoridades (20).

consignando alimentación de los trabajadores de caminos públicos" (AGN 1896. Prefecturas, Legajo 41. Anexo 20 de la Memoria sobre Loreto del Ministro de Guerra y Comisionado Especial y Extraordinario del Supremo Gobierno en el Departamento de Loreto).

(20) De hecho, el primer informe no provino de Sandoval sino, como se ha dicho, de Díaz. 
Tras la sublevación, "la indiada" se dispersó planteando la dificultad de castigar a los rebeldes, máxime con pocos efectivos policiales y con las rutas controladas por los insurrectos. Los hechos fueron considerados particularmente graves por los vecinos de Tarapoto, las autoridades de esa localidad y las de Moyobamba. Los primeros en pedir sanciones ejemplificadoras fueron 52 vecinos de Tarapoto convocados por el alcalde del Concejo Provincial quienes elevaron un oficio dirigido al prefecto de Loreto y al Presidente de la República pidiendo su intervención (AGN 1893. Prefecturas. Legajo 35. Documento del Honorable Concejo Provincial de Tarapoto al Prefecto de Loreto y al Presidente de la República 13/07/1893). Para ello se cuidaron de imputar toda responsabilidad de los hechos al "instinto feroz e indómito" de los indios, salvando cualquier responsabilidad que pudiera imputarse a los comerciantes locales que venían siendo criticados por el nuevo prefecto de Loreto. Sin embargo, sintomáticamente, en el documento incluían la solicitud al gobierno de que cuidara de nombrar a "personas que conozcan la índole del país y á sus habitantes en su mayor parte indígenas", deslizando la insinuación de que la autoridad que había sido víctima del levantamiento no conocía las costumbres del lugar (21).

En un principio el gobernador de Tarapoto informó al Subprefecto que el vecindario estaba "decidido a sacrificarse" para restablecer el orden (AGN. 1893. Prefecturas. Legajo 35. Oficio del Gobernador de Tarapoto al Subprefecto de Moyobamba. 12/07/1893). Sin embargo, al recibirse noticias de que los chasutas contaban con el "apoyo de los caceríos ( sic) circunvecinos de igual condición salvaje", las autoridades reconocieron sus limitaciones para organizar una fuerza "atendiendo al carácter local... y a la índole de sus vecinos" (mayoritariamente indígenas) y el riesgo de desguarnecer a los poblados movilizando la escasa fuerza pública (AGN 1893. Prefecturas, Legajo 35. Informe de A. Díaz al Director de Gobierno. 17/07/1893). La posibilidad de un levantamiento general hizo tomar cabal conciencia del peligro que este acontecimiento entrañaba. Por ello en sus invocaciones a las más altas autoridades del departamento y al Ministerio de Gobierno, los locales enfatizaron el "carácter salvaje" de los habitantes indígenas, su "ferocidad" y su "desconocimiento de sentimientos humanitarios". Además, acudiendo repetidamente a la poderosa imagen resultante de la muerte de los marinos Távara y West en 1866 a manos de indígenas cashibo del río Pachitea y del castigo infligido a éstos con ese motivo, se insistió en la idea de un castigo ejemplificador y se llegó a sugerir la necesidad de ocupar militarmente Chasuta por uno o dos años y de introducir gente blanca, mestiza e indios de otros poblados para así evitar el riesgo de futuros alzamientos.

\section{LA RUPTURA DEL PACTO COLONIAL CON LOS CHASUTAS, 1893}

¿Qué había pasado para que los chasutas, esta "raza dócil y tranquila" de 40 años atrás, reaccionaran con violencia ante la demanda de la autoridad de contribuir con

(21) El documento dice que "no hubo razones externas... los hechos inesperados obedecieron únicamente al instinto feroz e indómito de los habitantes" (AGN 1893. Prefecturas. Legajo 35. Documento del Honorable Concejo Provincial de Tarapoto al Prefecto de Loreto y al Presidente de la República 13/07/1893, cursivas mías). 
trabajo?(22) Sabemos que durante los treinta años transcurridos desde que la exportación de caucho y jebe empezó a experimentar un auge, la demanda de peones habitantes de las antiguas misiones había sido muy fuerte resultando en su despoblamiento masivo. A ello se había sumado una epidemia (de una enfermedad no identificada) que había "gravado" a la zona de Moyobamba en 1888 (AGN 1888. Prefecturas, Legajo 8. Oficio de Leonidas Avendaño al Director General de Gobierno. 18/09/1888). Sin embargo, sorprendentemente la población de Chasuta parece no haberse visto mermada en proporciones equivalentes a las de otras localidades. En 1893 Chasuta tenía 2000 habitantes, un 25\% más que la población calculada por Raimondi (1942: 56) en su segundo viaje.

Podemos ensayar algunas explicaciones respecto de este fenómeno, aunque ninguna puede ser conclusiva. Aún cuando hacia fines del siglo XIX el principal movimiento comercial del departamento se verificara en su parte oriental, la ruta del Huallaga no había perdido su importancia estratégica como lo demostraba la intención de dar mantenimiento al camino hacia Tarapoto. En el contexto de levantamiento, el puerto de Chasuta era considerado "la llave de la comunicación y comercio de las provincias del Huallaga y San Martín con las de Alto y Bajo Amazonas" (AGN 1893. Prefecturas. Legajo 35. Oficio de A. Díaz al Director de Gobierno. 29/07/1893). Además, esta ruta era la que podría asegurar un pronto traslado de tropas desde los departamentos aledaños, así como la comunicación con las autoridades de capital (23).

Es posible que la ubicación estratégica de Chasuta en esta ruta, sumada a la destreza de los chasutas, de quienes se dependía para el traslado de hombres y pertrechos en canoas y balsas, explicara el que su población no se viera tan fuertemente afectada por el enganche de peones para la extracción de gomas (24). En ese caso tendríamos que asumir que las autoridades locales, indígenas y políticas, los defendieron y protegieron de comerciantes habilitadores interesados en captar la tan demandada mano de obra catequizada para llevarlos a los frentes gomeros.

(22) En su carta al Director General de Gobierno Díaz llega a señalar: "Este proceder de salvajismo ha sido constante en Chazuta”, señalando a continuación que estos los hacía "igualables á los Cashibos, á los Foguinos (sic) ó á los Zulúes”... Estas comparaciones pretendían colocar a los chasuta en el último escalón de la barbarie..., argumento comprensible ante los hechos recientes. Sin embargo, estas expresiones son sorprendentes en el contexto del departamento de Loreto donde, aunque contrastados con los "blancos" los indígenas del Huallaga no dejaban de ser "salvajes", todo el mundo estaba de acuerdo en que éstos eran "civilizados" en contraste con los indígenas tribales del norte y oriente. Sólo afirmando esa condición era posible apelar al uso de la violencia como recurso natural y legítimo.

(23) Una línea telegráfica hacia Iquitos fue establecida algunos años más tarde. La comunicación por vía marítimo-fluvial, empleada para algunos propósitos, no tendría utilidad en caso de presentarse una situación de conflicto con Brasil como la que no dejaba de preocupar a las autoridades peruanas, particularmente desde 1892 en que dada la importancia del Yavarí, las autoridades aduaneras del Brasil disputaban la ubicación de la línea de frontera ante la desaparición de los mojones establecidos por la Comisión demarcadora binacional (AGN 1893. Prefecturas, Legajo 33. Oficio del Administrador de la Aduana de Leticia al Prefecto. Diciembre 1992).

(24) Nótese la expresión de Raimondi (1940: 300): “Aquí es donde se necesita toda la experiencia de los viejos Indios de Chasuta para dirigir la canoa, evitando que se voltee o que una grande oleada la sepulte". 
En ese sentido la presencia de Emilio Sandoval, quien actuaba como gobernador de Chasuta al momento del levantamiento, ofrece una pista conexa. A diferencia del gobernador en los tiempos de la visita de Spruce, que era un indígena, este personaje era un comerciante blanco-mestizo, ecuatoriano. Sandoval se había asentado en Chasuta 24 años atrás y, al decir del prefecto Rivera, era el único blanco que se había instalado de manera permanente y por tanto tiempo en la localidad. Tanto en sus informes de los hechos como en el manifiesto de los vecinos de Tarapoto se menciona que en su casa se hallaban depositados numerosos bultos de mercadería ("por valor de 50000 soles"), infiriéndose de ello que él, como autoridad o como particular, jugaba un destacado papel en el comercio de la región. Aunque carecemos de información acerca de en qué rubros comerciaba ni en qué empleaba a los indígenas chasuta como particular, es posible que él hubiera estado involucrado en la protección de los indígenas para la defensa de sus propios intereses comerciales pues dependía de los indios para conservar su papel de bisagra comercial entre el bajo y alto Huallaga. Su papel "protector" explicaría que tanto él como el cura conversor del pueblo salvaran sus vidas al momento del levantamiento (25).

Si los chasutas contaron con la protección del comerciante local con éste actuando como gobernador, ésta no era necesariamente la situación en el resto del Huallaga (26). Así, aunque indudablemente las afirmaciones que figuran en los partes del suceso estaban teñidas por la emoción del acontecimiento, es interesante mencionar que el prefecto Rivera anotaba: "Costumbre se está haciendo muy repetida en estos ríos que los indios asesinen a sus patrones".

Fuera el temor ante levantamientos como el que había ocurrido en San José de Sisa o por el interés de algunos patrones y autoridades en el arraigo de la mano de obra local, lo cierto es que ese mismo año las autoridades habían mostrado una inusitada postura frente a las continuas exigencias de prestación de servicios públicos. Mucha de la correspondencia oficial del año 1893 se refiere a la dificultad de conseguir postillones para el traslado de la correspondencia. Pocos meses antes del levantamiento, un oficio del subprefecto del cercado de Moyobamba indicaba que a las tasas presupuestadas para el pago de jornales para el traslado de correspondencia nadie quería hacer el servicio. Indicaba al mismo tiempo que anteriormente eso era posible sólo "bajo la acción de la fuerza bruta... que hoy ya no es posible ejercer" (AGN 1893. Prefecturas, Legajo 33. Oficio del Subprefecto del Cercado de Moyobamba al Director General de Gobierno. 25/04/1893). Sabiendo que en Loreto en general, incluyendo las zonas de indígenas catequizados, las autoridades no sólo eran cómplices de los enganchadores de peones sino que no dudaban en ejercer violencia para asegurar que los indígenas locales prestaran servicios público-privados, dicho comentario sugiere que, en el Huallaga, la administración étnica atravesaba un momento de crisis.

(25) Transcurridas tres semanas del levantamiento, tanto Sandoval como el cura y "los demás vecinos civilizados" optaron por dejar Chasuta para establecerse en Shapaja o Tarapoto.

(26) Definitivamente no la era en las áreas de avanzada cauchera. Hacia 1890 se registra varias denuncias acerca del papel que jugaban los gobernadores en Loreto con relación al reclutamiento forzado de los indígenas, particularmente en el caso de Andoas, sobre el río Pastaza (AGN 1893. Prefecturas, Legajo 33). 
No es que se hubiera llegado al punto en que las autoridades no pudieran seguir imponiendo la prestación de servicios a los indígenas catequizados. Como hemos visto, la realización de trabajos públicos por parte de los indígenas del Huallaga no sólo era una obligación largamente establecida, sino una costumbre consentida en la medida que en su organización intervenían las autoridades indígenas quienes determinaban los turnos y las condiciones de participación. Esta obligación no parece haber sido cuestionada por ninguna de las partes, aunque como se ha mencionado el trabajo público gratuito había sido prohibido varias décadas antes.

Tampoco los indígenas cuestionaban cotidianamente esta tradición, la que acaso en el contexto de los desplazamientos forzados y la violencia ejercida contra los indígenas había llegado a convertirse en un mecanismo que les permitía asegurar su sobrevivencia. De hecho, ante la convocatoria del subprefecto Bello al trabajo de reparación del camino a Tarapoto, los indígenas se negaron a realizar el trabajo alegando que ellos "sólo trabajaban en el río" y que en esto "nadie los ayuda" (27). Con esto implicaban que su obligación y faena anual consistía en limpiar el río de palos (AGN 1893. Prefecturas, Legajo 33. Oficio del Prefecto de Loreto al Director General de Gobierno. Yurimaguas, 20/08/1893). No cabía exigirles una obligación adicional y una que no correspondiera a la tradición. Al comentar los sucesos, el ex gobernador Díaz añadía que en efecto esto era así y que un intento suyo por asegurar la colaboración de los chasutas en 1891 en los trabajos de reparación del camino habían tenido "idéntico resultado" (AGN 1893. Prefecturas, Legajo 33. Carta de Abel Díaz al Director General de Gobierno. 28/08/1893).

Una referencia proporcionada por Pablo Díaz en su informe permite ubicarnos mejor en el contexto interno de Chasuta y aquilatar la situación del conflicto. Al describir el desarrollo de los acontecimientos luego que los indígenas "insultaran" al Subprefecto (es decir demandaran herramientas y se negaran a trabajar), Díaz anotaba que "en lugar de obedecer" a éste y colaborar en castigar a los cabecillas con el cepo, los "varayos y policías" no hicieron nada y que en cambio los invitaron a que se fueran del poblado. A su vez, como hemos visto, Sandoval informó que los indígenas de Chasuta lo habían increpado por haber traído al Subprefecto.

¿Qué significaba esta “desobediencia”? Aquí se propone que éste es un indicio más de que, al igual que los amotinados, las autoridades indígenas de Chasuta consideraban que la repetida demanda de trabajo en la reparación del camino a Tarapoto excedía las obligaciones de su gente. Esta exigencia que venía a imponer una faena adicional a la obligación anual de trabajo, desafiaba a la costumbre consentida — hecha parte de la cultura local- e implicaba la ruptura de el pacto establecido con la administración étnica misional y colonial y hasta entonces no protestada de manera clara por la administración republicana (28). Este pacto suponía, evidentemente, acuerdos no

(27) El trabajo de reparación del camino a Tarapoto implicaba la limpieza de tramos que atravesaran zonas boscosas, el arreglo de los escalones en el cerro Huayrapurina y la refacción de los varios tambos con sus pastizales, a la vera del mismo.

(28) Cabe anotar que en el Presupuesto del Concejo Provincial del Cercado de Moyobamba de 1896-1897 se consignaba como ingresos las costas cobradas a los que no concurren al trabajo de refacción de los caminos públicos que corresponden a esta provincia a razón de S/. 1,20 por persona, 
equilibrados y una dosis de coerción. Sin embargo, en el contexto de esta región de frontera violenta, este aspecto no desmerecía el hecho de que los acuerdos de prestación de servicios públicos (para la administración estatal y para el cura) daban a los indígenas catequizados un mayor margen para defenderse de las presiones externas. De allí que el pacto hubiera mantenido su vigencia y que los chasutas estuvieran decididos a que la tradición, la costumbre consentida, no fuera modificada .

El caso de los chasutas plantea una situación paradójica. Las disposiciones legales que, a la letra, buscaban a asegurar que los indígenas tuvieran iguales derechos que el resto de los habitantes del país, básicamente no fueron cumplidas. En el caso del Huallaga tampoco tuvieron efecto los intentos de convertirlos en ciudadanos por el procedimiento de igualarlos en sus derechos y obligaciones eliminando las castas. Los indígenas de la antigua misión alta siguieron constituyendo una suerte de cuerpo social diferenciado, afianzado en la existencia de obligaciones basadas en la tradición misional. Esta situación era refrendada y se asentaba en una categorización social de la población local donde en una gradiente civilizatoria, los indígenas catequizados, de tradición urbana y cultura misional, ocupaban una posición intermedia entre los blancomestizos y los "salvajes" o indígenas tribales (29). Esta posición intermedia y sus obligaciones basadas en la tradición, permitían a los chasutas y otros indígenas de esta categoría, gozar de ciertos derechos (incluido el reconocimiento del papel de sus autoridades locales), los mismos que estuvieron decididos a defender. En este contexto la persistencia de este régimen de "castas", que contradecía la noción de ciudadanos, implicaba una ventaja. Si bien no eran "ciudadanos" (en el sentido legal atribuido al término por la constitución), eran mucho más "ciudadanos" (en el sentido de haber adquirido ciertos importantes derechos consuetudinarios) que el resto de los indígenas de la región.

Esta situación paradojal ya se le había hecho evidente a Bolívar quién debió retractarse de las medidas dictadas para disolver las corporaciones indígenas ante la evidencia de que podía acarrear abusos. La novedad de este caso radica en el análisis de una situación poco explorada, la de los indígenas de antiguas reducciones misionales de la selva peruana en un contexto de cambio acelerado y en el análisis de sus reacciones y lectura del pacto colonial. Sin embargo, la hipótesis de la pervivencia y resquebrajamiento del pacto colonial a fines del siglo XIX planteada con relación a los chasutas, no puede ser hecha extensiva, de manera automática, a otras agrupaciones sociales de la región de igual origen, aunque para algunas de ellas haya indicios de que se encontraban en una situación de intranquilidad que estaba poniendo en jaque a las autoridades de la región. Pero además, la exploración ulterior de este fenómeno, en uno y otra caso demanda un mayor conocimiento del contexto económico de la región del

implicando que ya se había establecido formalmente la obligación de prestar servicios públicos, aunque no he podido establecer quiénes y desde cuando quedaban obligados (AGN 1896. Prefectura, Legajo 41. Anexo 20 de la Memoria sobre Loreto del Coronel Ibarra).

(29) No es sobreinterpretar demasiado el asumir que las repetidas referencias al salvajismo de los chasutas por parte de las autoridades contemporáneas al levantamiento que compartían los criterios de esta clasificación social, reflejan de alguna manera el resquebrajamiento del pacto colonial (ver comentarios equivalentes en los oficios de las autoridades y cartas de A. Díaz). 
Huallaga y de las estrategias de los propietarios y comerciantes blanco mestizos que no partieron hacia el Bajo Amazonas en busca de un porvenir en el auge gomero.

\section{DESENLACE}

El levantamiento no llegó a ser reprimido aunque no podamos deducir de ello que no hubiera represalias locales. El prefecto de Loreto, que se había embarcado en Iquitos al mando de 20 gendarmes llegó hasta Yurimaguas donde se detuvo. Desde allí informó a sus superiores que no tenía caso proseguir, afirmando que la mayoría se había refugiado en la orilla derecha del Huallaga internándose en el río Tigre que comunica con el Yanayacu y Ucayali. Como los propietarios blancos de la zona siguieran exigiendo la presencia de guardias y el castigo para los culpables, el Prefecto encargó al sargento mayor Rosell restablecer el orden en Chasuta tomando la plaza con el "auxilio del vecindario de Tarapoto", levantar sumarios "día y noche" si fuera necesario para conocer a los asesinos y perseguirlos en caso hubieran fugado (30). Pero esta acción tampoco tuvo lugar a pesar de que diez días más tarde el Prefecto informara que enviaría 25 gendarmes desde Moyobamba y 15 de Tarapoto. Como veremos, nada de eso se verificó porque se consideró necesario que los escasos gendarmes de Tarapoto y Moyobamba se quedaran en sus puestos y porque estaban de por medio otros intereses. En ese contexto, sin embargo, se mencionó la captura del "cabecilla consuetudinario", Angel La Torre (31).

Transcurrido más de un mes desde el levantamiento, el comerciante y gobernador de Tarapoto, Abel Díaz dirigió una carta al Director de Gobierno en Lima protestando por la inacción del prefecto Rivera (AGN 1893. Prefecturas, Legajo 33. Carta de Abel Díaz al Director General de Gobierno. 20/08/1893). En su llamado a dar castigo a los amotinados para evitar que cundiera el "mal ejemplo" en Loreto, Díaz criticaba al Prefecto al señalar que "todos esperaban" que el castigo se produjera "de forma instantánea", pero que él se limitó a ordenar la captura de los que llegaran a las provincias vecinas, informando que no había mucho que hacer pues la mayoría se había refugiado en la orilla derecha del Huallaga internándose en el río Tigre que comunica con el Yanayacu y Ucayali. Pero la crítica de Díaz apuntaba más allá, implicando al prefecto

(30) AGN 1893. Prefecturas, Legajo 33. Instrucciones del Prefecto de Loreto, Alejandro Rivera al Sargento Mayor Pedro Rosell para restablecer el orden en Chasuta. 10/08/1893. Tampoco se registra el encausamiento de ningún indígena por este motivo en la "Razón general de todas las causas criminales que existen en el Juzgado de $1^{\mathrm{a}}$. Instancia de las Provincias del Alto y Bajo Amazonas" que abarca los años 1888 y 1896 mandado confeccionar por el comisionado Ibarra Palacios (AGN 1896. Prefecturas. Legajo 42. Memoria sobre Loreto, Anexo 21E).

(31) Aunque éste puede haber sido un indio chasuta, no hay indicación clara de que lo fuera. Como había cierta intranquilidad en la región ante la amenaza de que se empezaría a aplicar el cobro de la Patente de Contribuciones en el Alto Amazonas, puede que éste fuera asociado a otros incidentes que se consideró estaban vinculados a un plan político que involucraba a personajes influyentes del Huallaga (AGN 1893. Prefectura, Legajo 33. Carta de Abel Díaz al Director de Gobierno. 20/08/1893; AGN 1893. Oficio del Prefecto de Loreto al Director de Gobierno en respuesta a averiguación sobre la situación política en Loreto. 15/08/1893). El propio Mariano José Madueño, promotor del levantamiento federalista de 1896 que ya entonces se iba armando fue por un tiempo (1891) Subprefecto y residente de Moyobamba. 
y al subprefecto de Yurimaguas en un acto ya no sólo de negligencia sino de connivencia (32). En efecto, Díaz denunciaba el hecho de que muchos de los chasutas no habían fugado por la ruta señalada por el Prefecto sino río abajo hacia la zona de Yurimaguas, donde se hallaban ubicadas varias haciendas ribereñas (33). Mencionando por su nombre a tres de estas haciendas, acusaba a "empresarios de Yurimaguas por interés propio mísero" de haber dado amparo en sus propiedades a decenas de indios chasutas y, al Prefecto, de haberlo sabido y no haber actuado en absoluto.

En este desenlace podemos apreciar el encuentro de varias fuerzas desestructuradoras del orden misional que daba sustento al pacto colonial que aún alcanzaba a los chasutas. Por un lado, la apertura de nuevos frentes gomeros resultaba en una renovada presión sobre la importante reserva de mano de obra del Huallaga. Dicha demanda iba en contra de los intereses de aquellos patrones-comerciantes del Huallaga que contaban con poder retener su acceso a esta reserva. Y naturalmente ésta ponía en riesgo a la población indígena local todavía amparada por su condición, no sólo de semi-civilizada, sino de ciudadano misional. Por otro lado, en el proceso de reordenar el espacio administrativo de Loreto, las autoridades provinciales, departamentales y nacionales desconocieron los arreglos sociopolíticos que habían estado vigentes en la región del Huallaga. Si bien esos arreglos daban pie a un estatus quo que no exoneraba a los indígenas de misión de una situación de subordinación, les daban un margen de protección frente a la impunidad con que los patrones actuaban frente a los otros indígenas de la región. Las crecientes presiones y la actitud del subprefecto Bello que desconocía la costumbre sin siquiera ofrecer a cambio herramientas "como debía haber mandado el Estado", fue por ello interpretada por los chasutas como una evidencia de la intención de desconocer el pacto colonial. Roto éste, los indígenas a su vez desconocieron las formas de la costumbre recurriendo a la violencia y al recurso de los símbolos.

No sabemos cuál fue el destino final de los chasutas que fugaron hacia las haciendas del Bajo Huallaga. Aunque existen evidencias de peones y pueblos enteros que nunca regresaron de los fundos y frentes gomeros (Stocks, 1981) (34), es también cierto que algunos lograban redimir sus deudas y regresar a sus tierras después de algún

(32) El entonces Subprefecto del Alto Amazonas, Antonio Menacho, fue posteriormente enjuiciado, en 1895 acusado de "plagio de indios, exacciones, insubordinación y otros delitos" por denuncia de la prefectura de Loreto, aunque no sabemos si la causa tuvo relación con este acontecimiento (AGN 1896. Prefecturas, Legajo 41. Anexo 21 de la Memoria sobre Loreto del Coronel Ibarra).

(33) Las haciendas ribereñas de la zona de Yurimaguas estaban especializadas en la producción de aguardiente de caña y ganado para abastecer a los centros poblados y frentes extractivos. Estos fundos no ocupaban a muchos peones estables pero recurrían a relaciones de habilitación para movilizar a cuadrillas de peones adicionales para la extracción de recursos y la preparación de pescado salado. El trato a los peones civilizados de estos fundos era menos violento pero no estaba exento de una dosis de coerción (Santos Granero \& Barclay, 2000).

(34) Algunos de estos pueblos misionales desaparecieron literalmente como sería el caso de la antigua misión de San Javier de Chamicuros (Stocks, 1981: 92). En 1859, Raimondi había reportado la existencia de 500 chamicuro en ese pueblo. Para 1876, su población había decrecido a 275. Diez años más tarde, Belisario Patow, un inmigrante alemán, convenció a las familias chamicuro restantes de trabajar para él en su hacienda ganadera Pampa Hermosa ubicada en el bajo Huallaga. Más tarde éste mudó consigo a "sus" peones chamicuro hacia el río Yavarí para que trabajaran en la extracción de 
tiempo. En los fundos los indígenas catequizados perdían su estatuto de indios de misión y su (aunque reducido) margen de autonomía aunque no perdieran su ubicación en la escala social de la región como indios "semi-civilizados". Como los forasteros de las épocas coloniales, dejaban de ser parte de su cuerpo social originario, integrándose al contexto de los fundos donde el patrón era su intermediario social y político. Allí, de todas maneras, el pacto colonial perdía vigencia.

Queda por explorar, en base a otras fuentes y casos, en qué medida o de qué manera la ruptura del pacto colonial afectó la existencia y continuidad de estos conglomerados sociales. Las reducciones misionales jesuíticas "crearon” identidades y grupos sociales en función de su propia definición del espacio social del Huallaga, imponiendo prácticas sociales, económicas y culturales que dieron sustento a un ordenamiento que sobrevivió a la disolución de las misiones. Pero la condición de ciudadanos misionales o étnicos no correspondía al ámbito de los individuos sino de los colectivos asociados a los pueblos que les daban identidad. Al mismo tiempo, estos pueblos - la mayor parte de los cuales aún existen- y sus pobladores indígenas retenían no ya su cultura solamente sino su posición en la estructura sociopolítica de la región en función de unos roles, obligaciones y derechos que la tradición había establecido. Desconocidos éstos, las dinámicas sociales condujeron paulatinamente a la "desaparición" de los conglomerados sociales de origen misional, entre ellos los chasutas. Con algunas diferencias de matiz, en su lugar fueron quedando los "cholos", reconocibles en su origen por sus "apellidos" étnicos. Sólo casi un siglo más tarde algunos de estos conglomerados han acudido a sus tradiciones para revivir una identidades y reclamar unos derechos que la historia de la región parecía haber desvanecido.

\section{Referencias citadas}

AGN, 1887-1896 - Prefecturas, Legajos MI 5 al 42; Lima: Archivo General de la Nación.

ABURTO COTRINA, C. O., 1999 - Políticas y métodos de evangelización en Maynas durante el siglo XVIII: definiendo los elementos de la cultura misionera. In: Un reino en la frontera. Las misiones jesuitas en la América colonia (S. Negro \& M. Marzal, coordinadores); Lima: Fondo Editorial de la Pontificia Universidad Católica-Ediciones Abya Yala.

BASADRE, J., 1964 - Historia de la República del Perú; Lima: Editorial Peruamérica, S.A. Quinta edición aumentada y corregida.

BARCLAY, F., 1998 - Sociedad y economía en el espacio cauchero ecuatoriano de la cuenca del río Napo, 1870-1930. In: Fronteras, colonización y mano de obra indígena en la amazonía andina (siglos XIX -XX) (P. García Jordán, editora): 127-240; Lima: Fondo Editorial de la Pontificia Universidad Católica del Perú-Universidad de Barcelona.

BLOCK, D., 1980 - In search of El Dorado: Spanish entry into Moxos, a tropical frontier, 15501767. Tesis doctoral, Universidad de Texas en Austin, 259p.

castilla. Se dice que sólo uno de estos peones sobrevivió y regresó. La mujeres y niños quedaron bajo la tutela de Patow y, tras su muerte, pasaron como herencia al hijo de este patrón. 
CONTRERAS, C. \& CUETO, M., 1999 - Historia del Perú contemporáneo, 312p; Lima: Red para el Desarrollo de las Ciencias Sociales en el Perú.

ESPINOSA PÉREZ, L., 1955 - Contribuciones lingüísticas y etnográficas sobre algunos pueblos indígenas del Amazonas peruano, T. I, 602p; Madrid: Consejo Superior de Investigaciones Científicas-Instituto Bernardino de Sahagún.

FIGUEROA, F. de, ACUÑA, C. \& Otros, 1986 - Informes de Jesuitas en el Amazonas, 368p; Iquitos: CETA. Monumenta Amazónica.

GROHS, W., 1974 - Los indios del Alto Amazonas del siglo XVI al siglo XVIII. Poblaciones y migraciones en la antigua provincia de Maynas, 133p. In: Estudios Americanistas de Bonn, 2; Bonn.

GUERRERO, A., 1993 - De sujetos indios a ciudadanos-étnicos: de la manifestación de 1961 al levantamiento indígena de 1990. In: Democracia, Etnicidad y Violencia Política en los Países Andinos (A. Adrianzen \& Otros): 83-102; Lima: IEP ediciones-IFEA.

HERNDON, W.L., 1991 - Exploración del valle del Amazonas, 504p.; Quito e Iquitos: Ediciones Abya-Yala - CETA. Monumenta Amazónica (Tomo I de la obra de W. L. Herndon \& Gibbon).

MARONI, P., 1988 - Noticias auténticas del famoso río Marañón seguidas de las relaciones de los PP. A. de Zárate y J. Magnin (1735-1740), 565p; Iquitos: CETA. Monumenta Amazónica.

MARTÍNEZ RIAZA, A., 1999 - Política regional y gobierno de la Amazonía peruana. Loreto (1883-1914). Histórica, 23(2): 393-462.

MATTOS, J. W. de, 1984 - Diccionario topographico do Departamento de Loreto na Republica do Perú, 252p.; Iquitos: CETA (reproducción en facsimil).

MURATORIO, B., 1987 - Rucuyaya Alonso y la historia social y económica del alto Napo 18501950, 341p.; Quito: Ediciones Abya Yala.

RAIMONDI, A., 1940 - El Perú. Tomo 1, Parte Preliminar, 341p.; Lima: Escuela Tipográfica Salesiana.

RAIMONDI, A., 1942 - Apuntes sobre la Provincia Litoral de Loreto, 159p.; Iquitos: Imprenta El Oriente.

SAN ROMÁN, J., 1975 - Perfiles históricos de la amazonía peruana, 240p.; Lima: Ediciones Paulinas-CETA.

SANTOS GRANERO, F., 1992 - Etnohistoria de la alta Amazonía, siglos XV-XVIII, 305p.; Quito: Ediciones Abya Yala.

SANTOS GRANERO, F. \& BARCLAY, F., 2000 - Tamed frontiers. Economy, society and civil rights in Upper Amazonia, 386p.; Boulder y Londres: Westview Press.

SCAZZOCCHIO, F., 1981 - La conquête des Motilones du Huallaga Central aux XVIIe et XVIII siècles. Boletín del Instituto Francés de Estudios Andinos, X(3-4): 99-111.

SPRUCE, R., 1996 - Notas de un botánico en el Amazonas y en los Andes, 749p.; Quito: Ediciones Abya-Yala.

STOCKS, A. W, 1981 - Los nativos invisibles. Notas sobre la historia y realidad actual de los Cocamilla del río Huallaga, Perú, 185p.; Lima: CAAAP.

TESSMANN, G., 1999 - Los indios del Perú nororiental. Investigaciones fundamentales para un estudio sistemático de la cultura, 486p.; Quito: Ediciones Abya Yala. 